Pontifícia U $_{\text {niversidane }}$ Católica $_{\text {do Rio de Janejro }}$

Alessandra Maia Terra de Faria

Do Social e do Político:
teorias da Representação Política

Dissertação de Mestrado

Dissertação apresentada como requisito parcial para obtenção do título de Mestre pelo Programa de PósGraduação em Sociologia e Política da PUC - Rio.

Orientador: Prof. Paulo Mesquita d'Avila Filho

Rio de Janeiro setembro de 2008 


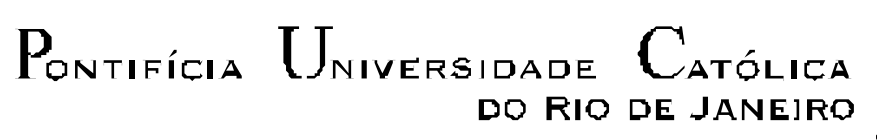

Alessandra Maia Terra de Faria

\title{
Do Social e do Político: teorias da Representação Política
}

Dissertação apresentada como requisito parcial para obtenção do título de Mestre pelo Programa de PósGraduação em Sociologia e Política da PUC-Rio. Aprovada pela Comissão Examinadora abaixo assinada.

\author{
Prof. Paulo Mesquita d'Avila Filho \\ Orientador \\ Departamento de Sociologia e Política - PUC-Rio
}

Prof. César Guimarães

IUPERJ

Prof. Bernardo Medeiros Ferreira da Silva

UERJ

Prof. Valter Sinder

Departamento de Sociologia e Política PUC-Rio

Prof. Nizar Messari

Coordenador Setorial do Centro

de Ciências Sociais - PUC-Rio

Rio de Janeiro, 12 de setembro de 2008 
Todos os direitos reservados. É proibida a reprodução total ou parcial do trabalho sem autorização da universidade, da autora e do orientador.

\section{Alessandra Maia Terra de Faria}

Graduourse em Ciências Sociais pelo Instituto de Filosofia e Ciências Humanas da UERJ em 2005. Os estudos envolvidos nesta pesquisa deram origem a artigos publicados no Brasil e no exterior.

Ficha Catalográfica

Faria, Alessandra Maia Terra de

Do social e do político: teorias da representação política / Alessandra Maia Terra de Faria ; orientador: Paulo Mesquita d'Avila Filho. - 2008.

$144 \mathrm{f.} ; 30 \mathrm{~cm}$

Dissertação (Mestrado em Sociologia e Política)-Pontifícia Universidade Católica do Rio de Janeiro, Rio de Janeiro, 2008.

Inclui bibliografia

1. Sociologia - Teses. 2. Política. 3. Representação política. 4. Democracia. 5. Participação política. I. D’Avila Filho, Paulo Mesquita. II. Pontifícia Universidade Católica do Rio de Janeiro. Departamento de Sociologia e Política. III. Título.

CDD: 301 
Para Alaíde e Florentinus Hennemann (in memoriam), Rosemary, Luiz Eduardo, Matheus e Nathalia, pela inspiração e carinho. 


\section{Agradecimentos}

Ao meu orientador Paulo Mesquita d'Avila Filho pelo estímulo, parceria e liberdade intelectual fundamentais para a concretização deste trabalho, e pelos longos debates que lhe deram vida.

À CAPES e à PUC-Rio, pelos auxílios concedidos, sem os quais este trabalho não poderia ter sido realizado.

Aos professores que participaram da Comissão Examinadora, César Guimarães, Bernardo Ferreira, e Valter Sinder pela leitura e reflexão sobre as questões expostas, que são o objetivo maior de qualquer pesquisa.

Ao corpo docente e discente do Departamento pelo ambiente propício ao conhecimento ao longo da elaboração deste trabalho. Principalmente aos professores Roberto DaMatta, Eduardo Raposo, Ricardo Ismael, Ângela Paiva, Marcelo Burgos e Sarah Telles pelos ensinamentos.

À professora Maria Alice Rezende de Carvalho por seus comentários valiosos e a interlocução para propostas de desenvolvimento futuro das questões aqui iniciadas.

Ao professor Valter Sinder, pela tranqüilidade e paciência transmitidas em nossas conversas ao longo do mestrado, e pelos ensinamentos metodológicos sobre a objetividade necessária para começar, desenvolver e terminar a dissertação.

À Ana Roxo e Mônica pelo prestativo apoio com a inextrincável burocracia. 
Aos membros do laboratório de estudos de Teoria Política da Uerj, em especial ao meu orientador de graduação professor João Trajano, pelas inúmeras aulas de teoria política, pelo gosto partilhado pelo pensamento político brasileiro e pelo incentivo nos estudos de filosofia e política desde a graduação.

Ao professor Marcelo Jasmin pelos ensinamentos sobre história das idéias e as discussões sobre traços da escola alemã e francesa, que foram muito úteis para este trabalho.

À Amanda Siqueira, Fernanda Tripolli e Daniela Tranches pela amizade e as incertezas compartilhadas. Ao companheirismo de Vera, Sandro, Leo, Eleandro, José Luiz, Samara, Gustavo, Pedro, Carmem, Débora, alguns amigos desde a graduação e outros conquistados ao longo do mestrado.

À minha extensa e querida família, que não caberia toda aqui. Em especial minha avó que hoje completaria setenta e sete anos e por toda sua vida incentivou meus estudos. À minha mãe Rose para quem me escapam as palavras, meu muito obrigado. À minha querida irmã e leitora Daniela e seus anjinhos Felipe e Marina, quantas alegrias. À minha querida irmã Márcia e André que me receberam em outro país, para que fosse possível divulgar este trabalho. À Flávio e Laura pelo apoio várias vezes recebido.

À luz dos meus dias, meus filhos Matheus e Nathi.

À Luiz Eduardo, meu marido, pela companhia na vida e nas escolhas e suas conseqüências, pelo partilhar dos momentos felizes, e o amparo nos dias tristes. Não teria conseguido sem você. 


\section{Resumo}

Faria, Alessandra Maia Terra de; D'avila Filho, Paulo Mesquita (Orientador). Do Social e do Político: Teorias da Representação Política. Rio de Janeiro, 2008. 144p. Dissertação de Mestrado - Departamento de Sociologia e Política, Pontifícia Universidade Católica do Rio de Jane iro.

O presente estudo abordará as teorias da representação política como expostas por Bernard Manin, Nadia Urbinati e Pierre Rosanvallon, sob a perspectiva de que a relação entre democracia e representação política é marcada por uma tensão inerente, como retomada por Bernard Manin. A retórica que acompanha a escalada do sufrágio universal como solução da tensão entre representação política e democracia faz com que a forma de entendimento da institucionalidade representativa esteja cercada de superstições quanto à eficácia e pujança de seus métodos. Interpelar a representação política enquanto um processo mediador destas tensões entre a esfera social e política é um movimento que aproximaria os três autores estudados. A questão é que para os dois primeiros, o processo de representação seria pré-estabelecido e, portanto, fechado e não permeável às mudanças, onde o mundo da política é claramente delimitado. Enquanto que para o terceiro, por uma postura diferenciada no que concerne à relação entre o social e o político, parece haver uma perspectiva singular de processo em aberto a ser considerada, traduzida em uma concepção de política expandida e contraditória, ou seja, do social e do político em intersecção.

\section{Palavras-chave}

Política; representação política; democracia; participação política. 


\section{Abstract}

Faria, Alessandra Maia Terra de; D’avila Filho, Paulo Mesquita (Advisor). The Social and the Political: Theories of Political Representation. Rio de Janeiro, 2008. 144p. Master's Dissertation. Department of Sociology and Politics, Pontifícia Universidade Católica do Rio de Jane iro.

The research herein deals with the theories of political representation as they are exposed by Bernard Manin, Pierre Rosanvallon and Nadia Urbinati, considering the perspective of a tense existing relationship between democracy and political representation, as it was recovered by Bernard Manin. There is a rhetoric that follows the universal suffrage adoption in which it is seen as a solution to the tense relationship among political representation and democracy, what has led general understanding of representative institutionality to be surrounded by superstitions regarding its mechanisms effectiveness and responsiveness. It is possible to approximate the three studied theorists if political representation is inquired as a process that mediates these tensions between political and social spheres. The question is that for both former authors, the political representation process is pre-established and, thus, closed and not permeable to changes, where the world of politics is clearly delimitated. While to the later, a different attitude towards the relationship between the social and the political seems to assure a singular perspective of open process to be considered, traduced in an expansive and contradictory conception of politics, in others words, of social and political intersection.

\section{Key-words}

Politics; political representation; democracy; political participation. 


\section{Sumário}

$\begin{array}{lr}\text { 1. Introdução } & 12\end{array}$

2. Dos eleitos e dos eleitores 22

2.1. Um pequeno aparte sobre mandato imperativo e mandato livre

2.2. Relação política, poder, direitos e voto

2.3. A opção pelas eleições: da antiguidade à modernidade- do sorteio democrático e do caráter aristocrático da eleição para Bernard Manin

2.4. Uma leitura sobre as descrições da passagem ao governo representativo feitas por Bernard Manin segundo três grandes inversões

3. O social e o político

3.1. Da tradução do social no político para Nadia Urbinati : premissas gerais

3.2. Da tradução do social no político para Nadia Urbinati: a relação Estado/sociedade 
3.3. Pierre Rosanvallon - um novo terreno interpretativo da representação política

3.4. O social e o político para Pierre Rosanvallon: o trabalho da representação

4. As temporalidades da representação política: além do sufrágio universal

4.1. Sobre representação política e as categorias de temporalidade, institucionalidade e normas/ procedimentos.

4.2. Diagnóstico de crise: três formas de refutar a crise da representação política

4.3. Desconfiança e contra-democracia: formas de institucionalidade e coexistência contraditória com a representação segundo Pierre Rosanvallon

4.4. Liberdade para pensar novos mecanismos além do sufrágio universal: considerações finais sobre possibilidades de relação entre social e político.

5. Observações Finais

6. Referências Bibliográficas 
Há um governo exercido segundo o interesse dos governantes e outro no interesse dos governados. $O$ primeiro é despótico; o segundo é um governo de homens livres.

Aristóteles

Le qualicatif italien scelti a, comme le terme fraçais "choisi" le double sens d'élu et de distingué.

Bernard Manin

Yet only a tiny minority of theorists assumes that representation is not alternative to but in fact supports democratic participation.

Nadia Urbinati

Représenter la société consiste à briser le voile d'abstration qui la recouvre pour lui redonner vie.

Pierre Rosanvallon

O adulto alivia seu coração do medo e goza duplamente de sua felicidade quando narra sua experiência. A criança recria essa experiência, começa sempre de novo, desde o $i$ nício. Talvez seja esta a raiz mais profunda do duplo sentido da palavra alemã Spielen (brincar e representar): repetir o mesmo seria seu elemento comum. A essência da representação, como da brincadeira, não é "fazer como se", mas "fazer sempre de novo", é a transformação em hábito de uma experiência devastadora.

Walter Benjamin 